\title{
Development of Clindamycin-Loaded Wound Dressing with Polyvinyl Alcohol and Sodium Alginate
}

\author{
Jong Oh KIm, ${ }^{b}$ Jun Young ChoI, ${ }^{a}$ Jung Kil PARK, ${ }^{a}$ Jeong Hoon KIm, ${ }^{b}$ Sung Giu JiN, ${ }^{b}$ Sun Woo Chang, ${ }^{b}$ \\ Dong Xun LI, ${ }^{a}$ Ma-Ro Hwang, ${ }^{a}$ Jong Soo Woo, ${ }^{a}$ Jung-Ae KIM, ${ }^{a}$ Won Seok Lyoo, ${ }^{c}$ \\ Chul Soon YoNG, ${ }^{*, a}$ and Han-Gon CHOI ${ }^{*, a}$ \\ ${ }^{a}$ College of Pharmacy, Yeungnam University; ${ }^{c}$ School of Textiles, Yeungnam University; $214-1$ Dae-Dong, Gyongsan \\ 712-749, South Korea; and ${ }^{b}$ Dong-A Pharm. Co., Ltd.; Yongin-Si, Kyunggi-Do 449-905, South Korea. \\ Received March 25, 2008; accepted August 25, 2008; published online September 10, 2008
}

To develop a clindamycin-loaded wound dressing, cross-linked hydrogel films were prepared using freezethawing method with various mixtures of polyvinyl alcohol (PVA) and sodium alginate (SA). The physicochemical properties such as swelling ratio, tensile strength and elongation of hydrogels were evaluated. The drug release from this clindamycin-loaded hydrogel, in vitro protein adsorption test and in vivo wound healing observations in rats were then performed. Increased SA concentration decreased the gelation \%, maximum strength and break elongation, but it resulted into an increment in the swelling ability, elasticity and thermal stability of hydrogel film. However, SA had insignificant effect on the release of clindamycin. This hydrogel improved the healing rate of artificial wounds in rats. Thus, a clindamycin-loaded wound dressing with PVA and SA hydrogel should be a candidate for wound care.

Key words clindamycin; sodium alginate; polyvinyl alcohol; hydrogel; wound dressing

A large number of dressings are currently used in the management of burns, split graft donor sites, chronic ulcers, decubitus ulcers, and so on. ${ }^{1-4)}$ There are two kinds of dressings: dry type and wet type. It has been reported that healing with a wet environment is faster than that with a dry environment. ${ }^{5}$ In recent years, hydrogels have received considerable attention to be used as specific absorbents in wound dressing materials. Thus, a number of polymers with superabsorbent properties have been developed for clinical applications, such as liquefaction and removal of scar, treatment of leg ulcers, pressure sores, and prevention of tissue deterioration in patients with restricted mobility. However, in the case of severe infections, the wound dressing hydrogelsonly with polymers may be insufficient for treatment of infection. Therefore, topical antimicrobial therapy remains one of the most important methods of skin wound care. The local application of antibiotics can provide high drug concentrations at the site of infection and can avoid systemic effects. ${ }^{6}$ )

In this study, to develop a clindamycin-loaded wound dressing, cross-linked hydrogel films were prepared using freeze-thawing method with various mixtures of polyvinyl alcohol (PVA) and sodium alginate (SA). The physicochemical properties such as swelling ratio, tensile strength, elongation and thermal stability of hydrogels were evaluated. The drug release from this clindamycin-loaded hydrogel, in vitro protein adsorption test and in vivo wound healing observations in rats were then performed.

Clindamycin [7(S)-chloro-7-deoxylincomycin], a lincosamide antibiotic is active against aerobic Gram-positive and anaerobic bacteria, mycoplasmas, and some protozoa. ${ }^{7)}$ In companion animal medicine, clindamycin is mainly used in the treatment of diseases like staphylococcal skin infections and osteomyelitis, periodontal disease, bacterial prostatitis, toxoplasmosis, and neosporosis.

Polyvinyl alcohol (PVA) has several useful properties including non-toxicity, biocompatibility, high hydrophilicity, fiber/film forming ability, and the chemical and mechanical resistance ${ }^{8)}$ PVA hydrogels produced by using the freezingthawing technique form a matrix of physically crosslinked polymeric chains containing uncrosslinked polymer and water. These gels are non-toxic, non-carcinogenic, have good biocompatibility, and have desirable physical properties such as rubbery nature and high degree of swelling in water. ${ }^{9)}$ PVA must be crosslinked if it is to be used in biodegradable materials. Furthermore, sodium alginate has been widely used in medical application such as wound dressings, scaffolds for hepatocyte culture and surgical or dental impression material. ${ }^{10,11)}$ It is hydrophilic, biocompatible, and relatively economical. ${ }^{12)}$ It has been successfully applied to cleanse a wide variety of secreting lesions due to its high absorption.

\section{MATERIALS AND METHODS}

Materials PVA (typical average $M_{\mathrm{w}}=146000-186000$; $99+\%$ hydrolyzed), sodium alginate, climdamycin $((7 S)-7$ chloro-7-deoxylincomycin hydrochloride), human serum albumin (HSA) $\left(M_{\mathrm{w}}=66 \mathrm{kDa}\right.$, albumin: $\left.97.31 \%\right)$ and human plasma fibrinogen (HPF) $\left(M_{\mathrm{w}}=341 \mathrm{kDa}\right.$, clottable proteins $>95 \%$ ) were purchased from Sigma-Aldrich, Kanto Chemical Co. (Tokyo, Japan), Fluka Co. (Germany) and Calbiochem Co. (Germany), respectively. All other chemicals were used without any further purification.

Preparation of Hydrogels PVA/SA hydrogels were obtained by freezing-thawing (F-T) cycle. ${ }^{9)}$ Solutions containing $10 \% \mathrm{w} / \mathrm{v}$ PVA and $3 \% \mathrm{w} / \mathrm{v}$ SA and clindamycin were prepared in deionized water. Different proportions of PVA and SA (SA $=0,5,10,20,30 \%)$ solutions were mixed by vortexing for an hour, and the calculated amounts of this mixture were poured in petri dishes, followed by freezing at $-20^{\circ} \mathrm{C}$ for $18 \mathrm{~h}$ and thawing at room temperature for $6 \mathrm{~h}$, for three consecutive cycles.

Determination of Gel Fraction After three F-T cycles, the samples were dried for $6 \mathrm{~h}$ at $50^{\circ} \mathrm{C}$ in an oven $\left(W_{\mathrm{o}}\right)$, then soaked in distilled water for $24 \mathrm{~h}$ up to a constant weight in 
order to remove the soluble parts. The gels were then dried again at $50{ }^{\circ} \mathrm{C}$ in an oven $\left(W_{\mathrm{e}}\right)$. The gelation \% was then calculated by the following equation. ${ }^{13)}$

gelation $\%=\left[W_{\mathrm{e}} / W_{\mathrm{o}}\right] \times 100$

where $W_{\mathrm{o}}$ and $W_{\mathrm{e}}$ are the weights of hydrogel samples dried for $6 \mathrm{~h}$ at $50^{\circ} \mathrm{C}$ before and after soaking, respectively.

Determination of Swelling Ratio To measure the swelling behavior, hydrogel samples were cut into $2 \mathrm{~cm} \times$ $2 \mathrm{~cm}$ pieces and dried at $50^{\circ} \mathrm{C}$ in an oven for $1 \mathrm{~h}$ and their dry weights $\left(W_{\mathrm{a}}\right)$ were immediately measured, then they were soaked in PBS maintained at $37^{\circ} \mathrm{C}$ and their weights $\left(W_{\mathrm{s}}\right)$ were determined at specific time points and the swelling ratio (SR) was calculated using the following formula:

$$
\mathrm{SR} \%=\left[W_{\mathrm{s}} / W_{\mathrm{a}}\right] \times 100
$$

where $W_{\mathrm{a}}$ and $W_{\mathrm{s}}$ are the weights of hydrogel samples dried for $1 \mathrm{~h}$ at $50^{\circ} \mathrm{C}$ and soaked in PBS maintained at $37^{\circ} \mathrm{C}$, respectively.

Changing of $20 \%(\mathrm{w} / \mathrm{w})$ sample's weight was also observed for $30 \mathrm{~min}$. To minimize error caused by surface water, weights after immediate soaking $\left(W_{\text {si }}\right)$ were also taken. The swelling ratio $\left(\mathrm{SR}^{\prime}\right)$ was then determined according to the following formula. ${ }^{13-15)}$

$$
\mathrm{SR}^{\prime} \%=\left[\left(W_{\mathrm{s}}-W_{\mathrm{si}}\right) / W_{\mathrm{a}}\right] \times 100
$$

where $W_{\mathrm{s}}$ and $W_{\mathrm{si}}$ are the weights of hydrogel samples soaked in PBS maintained at $37^{\circ} \mathrm{C}$ immediately and for $30 \mathrm{~min}$, respectively.

Determination of Mechanical Properties The tensile strength and breaking elongation of hydrogels were determined using a tensile test machine (Instron 4464, U.K.). After three F-T cycles, the hydrogels were cut into specific dog bone shape $(6 \mathrm{~cm}$ long, $2 \mathrm{~cm}$ wide at the ends and $1 \mathrm{~cm}$ wide in the middle). The mechanical analysis was performed at a stretching rate of $20 \mathrm{~mm} / \mathrm{min}$ with pre-load of $0.5 \mathrm{~N}$ to determine the maximum load for each matrix. The thickness of each individual hydrogel was also measured. ${ }^{13,16,17)}$

Adsorption of Protein onto Hydrogel Surface Pieces of hydrogel membrane cut into $2 \mathrm{~cm} \times 2 \mathrm{~cm}$ were immersed in $4 \mathrm{ml}$ of $\mathrm{pH} 7.4$ phosphate buffer solution (PBS) containing HSA and HPF proteins at $37^{\circ} \mathrm{C}$, and shaken at $100 \mathrm{rpm}$ for $24 \mathrm{~h}$. Samples were then gently taken out and rinsed five times with PBS, placed in six wells containing aqueous solution of $1 \%$ sodium lauryl sulfate and shaken for $1 \mathrm{~h}$ at room temperature to remove the protein adsorbed on the surface. The protein contents of the each sample were then measured using the Bradford reagent. The absorbance at $570 \mathrm{~nm}$ was measured using an ultraviolet spectrometer. The calibration curve was prepared by measuring varying protein concentrations in the solution. ${ }^{16,17)}$

Dissolution The drug release from hydrogel was measured by using Teflon frame instrument. Only one side of sample was attached to the Teflon frame instrument that was immersed into $400 \mathrm{ml}$ distilled water at $37^{\circ} \mathrm{C}$ as the dissolution medium and stirred at the paddle speed of $50 \mathrm{rpm}$. One milliliter of the sample was withdrawn from the medium at various time intervals. The concentration of drug was determined by high-performance liquid chromatograph (PU-987 pump and UV-975 UV detector, Jasco). Then, $50 \mu \mathrm{l}$ of the samples were injected into the column $(5 \mu \mathrm{m}$ particle size,
$4.6 \times 150 \mathrm{~mm}$, Inertsil C18, GL Science) with a UV detector at $214 \mathrm{~nm}$. The mobile phase was acetate buffer $(\mathrm{pH} \mathrm{4.6)-}$ acetonitrile $(75: 25, \mathrm{v} / \mathrm{v})$ at $1 \mathrm{ml} / \mathrm{min} .6,18,19)$

In Vivo Wound Healing Test Male SD rats weighting approximately 250 - $300 \mathrm{~g}$ was used to evaluate wound healing characteristics of hydrogels. The dorsal hair of rats was shaved and the animals were anesthetized with Zoletil50 ${ }^{\circledR}$ (Tiletamine/Zolazepam)/Rompun ${ }^{\circledR}$ (Xylazine) cocktail by IP injection. Two full thickness skin wounds of $1.5 \mathrm{~cm} \times 1.5 \mathrm{~cm}$ area were prepared by excising the dorsum of rats and disinfected using $70 \%$ ethanol. The excised wounds were covered with the ethylene oxide gas sterilized PVA/SA wound dressings $(2 \mathrm{~cm} \times 2 \mathrm{~cm})$ containing clindamycin (control sample contained no drug) and fixed with elastic adhesive bandage (Soft cloth tape $^{\circledR}, 3 \mathrm{M}$ ). After the experiment, rats were sacrificed by excess diethyl ether on 5 and $15 \mathrm{~d}$ after surgery. The wounds were grossly examined and photographed for characteristics evaluation. ${ }^{14,20)}$

Histopathology For histopathological study, the skins including the entire wound with adjacent normal skin were excised and fixed in 10\% buffered formalin. The specimen included the dermis and the subcutaneous tissue. Excised wound sites fixed in formalin were processed and embedded in paraffin, and sections of $3-5 \mu \mathrm{m}$ were stained with hematoxylin and eosin..$^{21-23)}$

\section{RESULTS AND DISCUSSION}

Freeze-thawed solution leads to the formation of insoluble hydrogel. The more sodium alginate increased, the less gel fraction decreased (Fig. 1). The gel fraction in absence of SA was about $85 \%$ and relatively high, suggesting that PVA was almost completely crosslinked. ${ }^{24)}$ Gel fraction decreased to less than $60 \%$ at $30 \%$ SA concentration with increasing SA concentration. In addition to acting as a wound healer, SA also reduces the crosslinking reaction and consequently the gelation process. Furthermore, in F-T cycle, the crosslinking strength of SA was weaker than that of PVA, even though SA formed crosslinking bond with PVA in the gel. Generally, as the gel fraction was lower, the strength and less flexibility of gel was weaker. ${ }^{13)}$ This effect can be utilized to control the gel fraction and strength of hydrogel.

Figure 2A shows the effect of the maximum swelling abil-

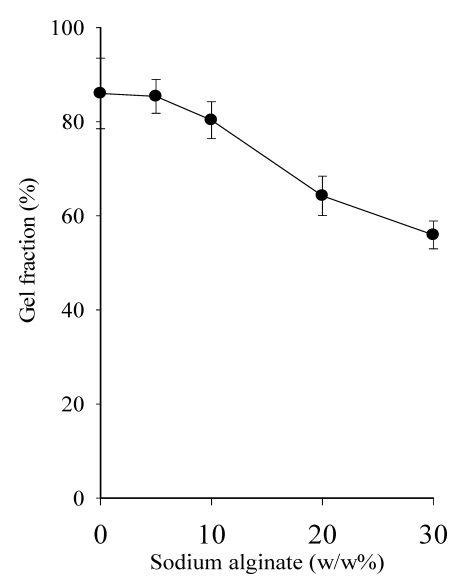

Fig. 1. Effect of SA on Gel Fraction

Data are expressed as mean \pm S.D. $(n=3)$. 
(A)
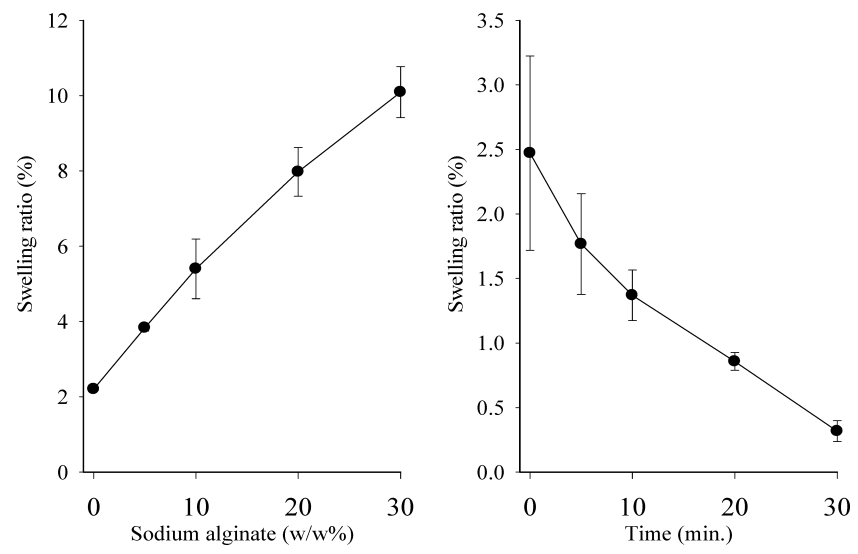

Fig. 2. Effect of SA on Maximum Swelling Ratio of Hydrogel Dressings (A) and Swelling Ratios of $20 \%$ SA-Loaded Hydrogel Dressings with Respect to Time (B)

Data are expressed as mean \pm S.D. $(n=3)$.

ity on the SA proportion. It can be seen that the maximum swelling ability increased with increased SA proportion. SA has better swelling ability, because it doesn't crosslink and is soluble in water. Lowly crosslinked hydrogels tended show higher water uptake ability, since the highly crosslinked structure couldn't sustain much water within gel structure. ${ }^{14,15}$ Figure $2 \mathrm{~B}$ shows the swelling kinetics of $20 \%$ hydrogel dressings. Initially, swelling rate was very high, and the water could be absorbed easily into the hydrogel. However, swelling decreased after the elapse of time, due to the loss of SA because of its solubility.

To investigate the influence of SA on the mechanical properties of PVA/SA hydrogel, tensile strength and elongation at break were evaluated. Both the maximum strength and elongation at break decreased with increasing SA portions (Fig. 3A). The decrease of the tensile strength was believed to be due to decreased crosslink density. ${ }^{25)}$ From the Young's modulus curve (Fig. 3B), it can be seen that the more elastic hydrogels were obtained with an increment in SA proportions. ${ }^{26)}$ Furthermore, the maximum strength at break gave the same pattern to Young's modulus. Thus, our results suggested that sodium alginate decreased the maximum strength of hydrogels, resulting in strengthening the elastic property of hydrogel. Our results suggested that the crosslink between PVA and SA was not strong compared to the crosslink between PVA itself. Thus, whereas PVA was hard and close to solid, PVA/SA mixed hydrogels displayed more flexibility and elasticity.

Figure 4 showed the albumin (HSA) and fibrinogen (HPF) adsorptions onto the PVA/SA membranes and the albumin/ fibrinogen adsorption ratio (HSA/HPF). The albumin/fibrinogen adsorption ratio is important when assessing the adhesion of platelets to artificial surfaces. Furthermore, the higher was the albumin/fibrinogen adsorption ratio, the lower was the number of adhering platelets. ${ }^{27)}$ Both the adsorption of HSA and HPF hardly changed as the amounts of SA in the PVA hydrogels increased. Thus, SA had insignificant effect on the albumin/fibrinogen adsorption ratios tested, suggesting that SA hardly affected the adhesion of platelets to artifi-
(A)
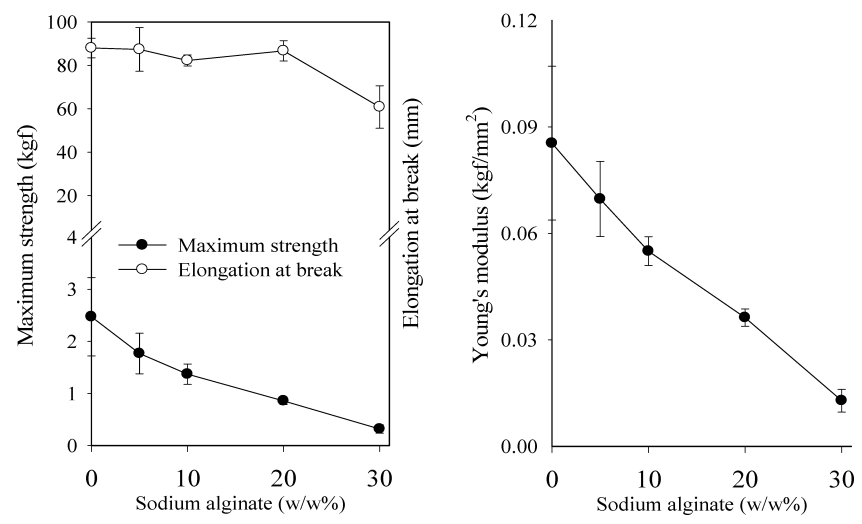

Fig. 3. Effect of SA on Maximum Strength and Elongation at Break (A), and Young's Modulus (B)

Data are expressed as mean \pm S.D. $(n=3)$.

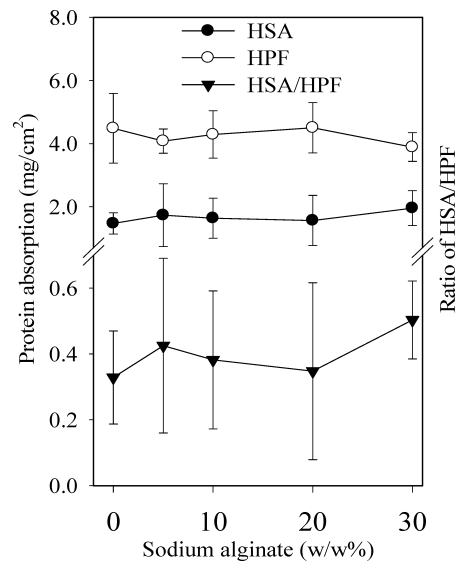

Fig. 4. Effect of SA on Protein Adsorption and HSA/HPF Adsorption Ratios

Data are expressed as mean \pm S.D. $(n=3)$.

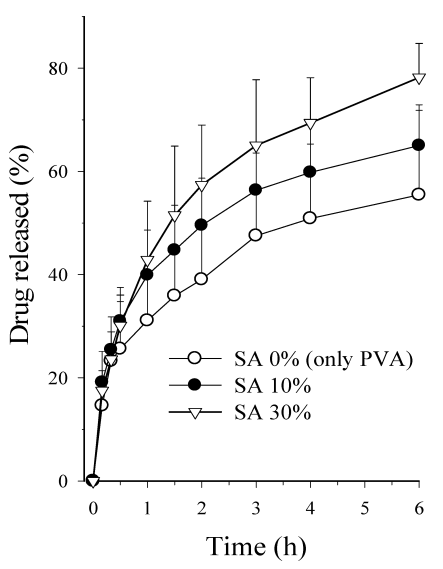

Fig. 5. Effect of SA on the Dissolution of Clindamycin Data are expressed as mean \pm S.D. $(n=3)$.

cial surfaces.

To evaluate whether sodium alginate affected the release rates of clindamycin, the release studies on various clindamycin-loaded hydrogels were carried out (Fig. 5). The release rate of clindamycin in the hydrogel with $10 \% \mathrm{SA}$ 
(a) At 0 day

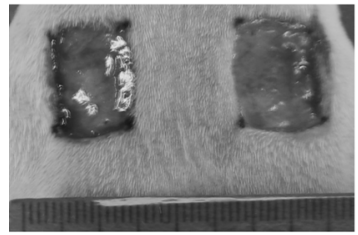

(b) After 5 days ( $L$ : control, R : only PVA )

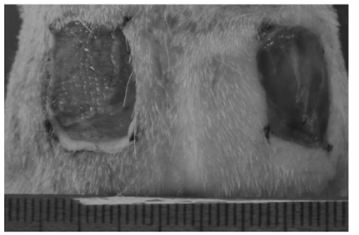

(c) At 0 day

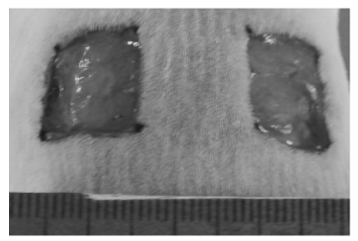

(e) At 0 day

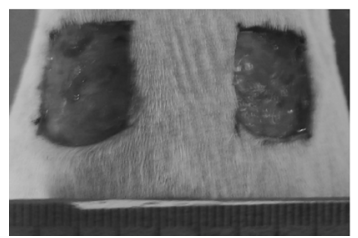

(d) After 5 days ( L: control, R : 10 w/w $\%$ SA)

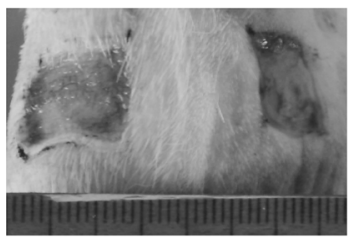

(f) After 5 days ( $\mathrm{L}$ :control, R : $30 \mathrm{w} / \mathrm{w} \% \mathrm{SA}$ )

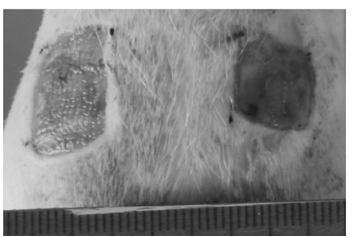

Fig. 6. Representative Photographs of Wound Spot at 0 and $5 \mathrm{~d}$

hardly changed compared to hydorgel with only PVA in distilled water. Furthermore, the release rate of clindamycin in the hydrogel with $30 \%$ SA a little increased compared to hydorgel with only PVA but there was no significant difference. Therefore, SA hardly affected the clindamycin release behavior from hydrogels.

Each wound was observed for a period of 5 and $15 \mathrm{~d}$ post operation. All rats survived throughout the postoperative period until sacrifice. The healing process for each wound treated by dressing application progressed satisfactorily without any apparent complications. There were no evidences of necrosis. At $5 \mathrm{~d}$ postoperatively (Fig. 6), little discrete inflammation was observed. There was no evidence of infection or contraction of the wound, whereas skin was hemorrhagic for some control samples and also scab was present on the wound spot. There was no size reduction in wound defect area of every sample. At $15 \mathrm{~d}$ postoperatively (Fig. 7), majority of the wounds appeared to be healed. Exhibited an external cicatrisation but almost completely sealed.

Healing pattern of wounds was studied by the histology of control, SA $0 \%(\mathrm{w} / \mathrm{w}), 10 \%(\mathrm{w} / \mathrm{w})$ and $30 \%(\mathrm{w} / \mathrm{w})$ at 5 and $15 \mathrm{~d}$ postoperatively (Figs. 8, 9). ${ }^{14,28)}$ On the 5 th day of postwounding, histology analysis showed that test and control wounds showed an inflammation (Fig. 8). Inflammatory phase is essential to healing. More inflammatory cells were seen in the test wound. Granulation tissue formation was also observed. These results suggested that moist environment accelerated wound healing at $5 \mathrm{~d}$ of post wounding. At $15 \mathrm{~d}$, in PVA/SA wounds, the defect area almost was completely regenerated and showed a central small size wound (Fig. 9). However, control wounds didn't completely covered with new epithelium and still showed inflammatory cell. As SA proportion increases, more inflammatory cells were observed. It was due to macrophage and biomaterial interactions.

(a) At 0 day

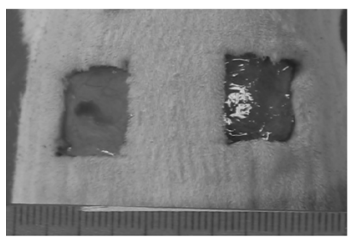

(c) At 0 day

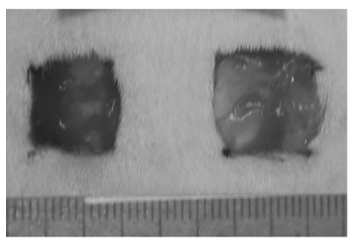

(e) At 0 day

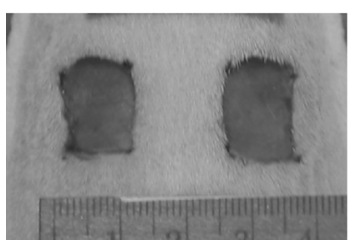

(b) After 15 days ( L: control, R: only PVA )

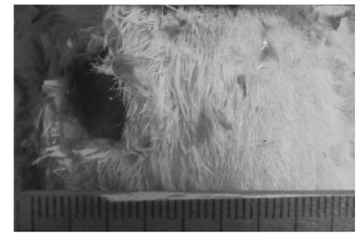

(d) After 15 days ( L: control, R: 10w/w\% SA )

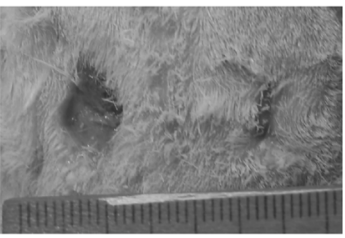

(f) After 15 days ( $L$ : control, R: 30w/w\% SA )

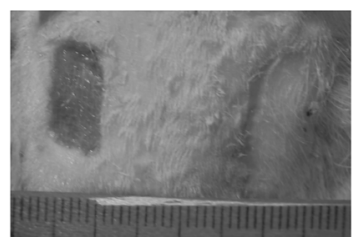

Fig. 7. Representative Photographs of Wound Spot at 0 and $15 \mathrm{~d}$
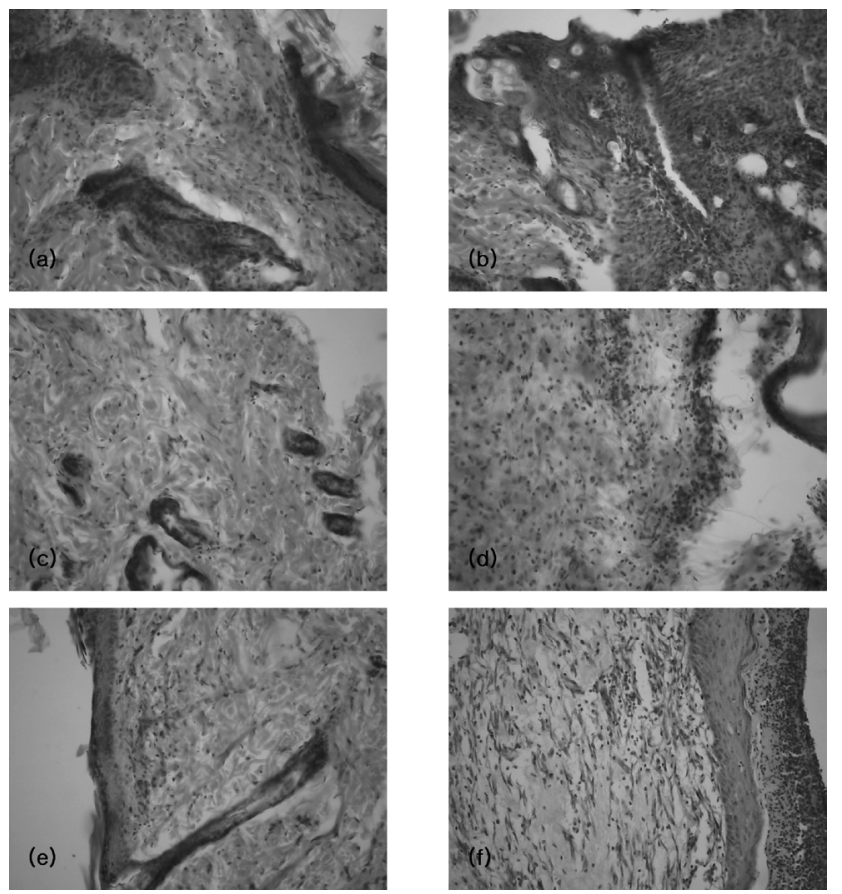

Fig. 8. Histological Studies

Left photographs (a, c, e) and right photographs (b, d, f) were at $5 \mathrm{~d}$ after injury. (a, c, $\mathrm{e}=$ only guaze, $\mathrm{b}=30 \%(\mathrm{w} / \mathrm{w}) \mathrm{SA}, \mathrm{d}=10 \%(\mathrm{w} / \mathrm{w}) \mathrm{SA}, \mathrm{f}=$ only PVA $) . B a r=40 \mu \mathrm{m}$. $\times 100$.

The effect of clindamycin on the wounds and healing pattern of wounds were evaluated by examining the histology of only gauze (control), the PVA hydrogel without clindamycin and the PVA hydrogel with clindamycin at $5 \mathrm{~d}$ of post operation On the 5th day of post wounding, more inflammatory cells were found in control wounds treated with hydrogel without drug (Figs. 10a,c,e). However, the hydrogel with drug showed a significant effect on wound (Figs. 10b, d, f). 

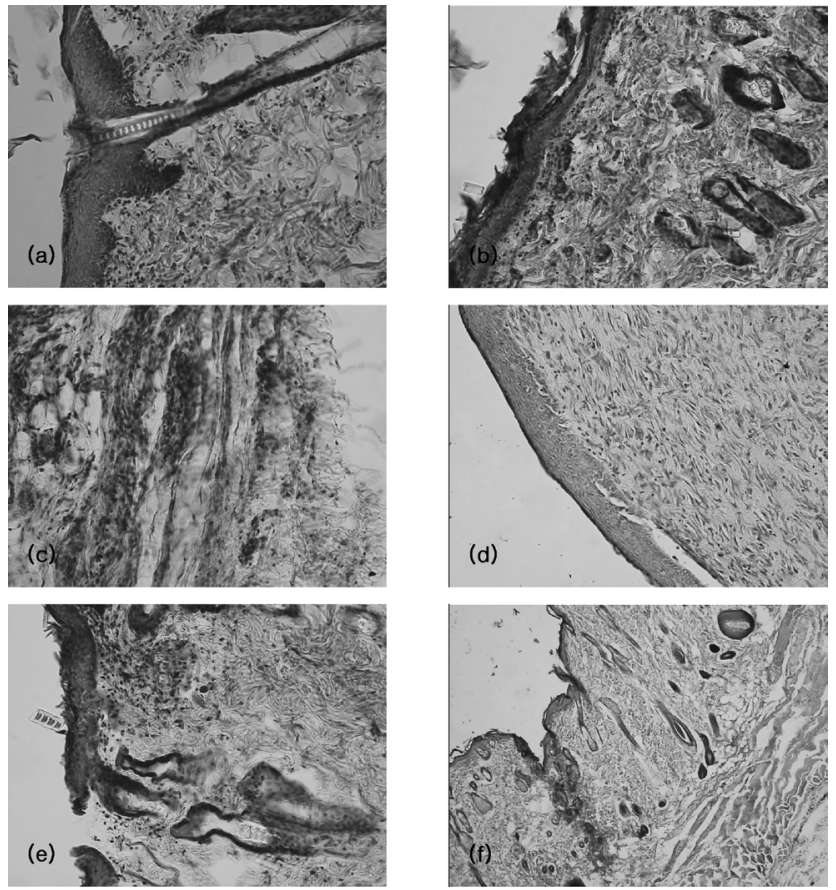

Fig. 9. Histological Studies

Left photographs (a, c, e) and right photographs (b, d, f) were at $15 \mathrm{~d}$ after injury. (a

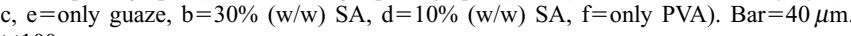
$\times 100$.
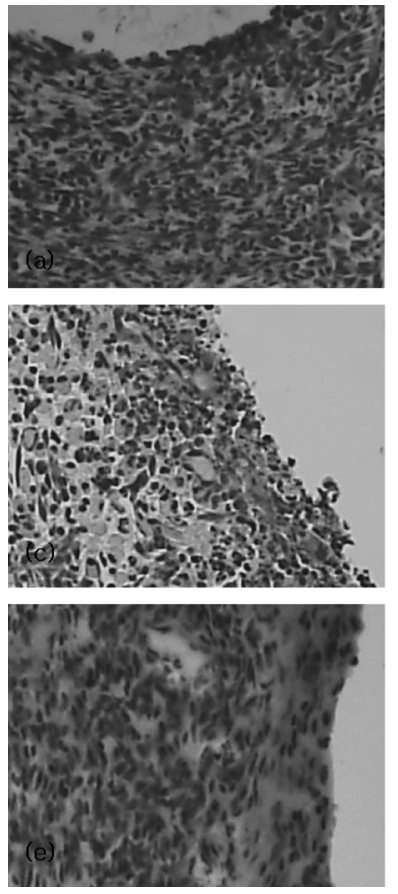
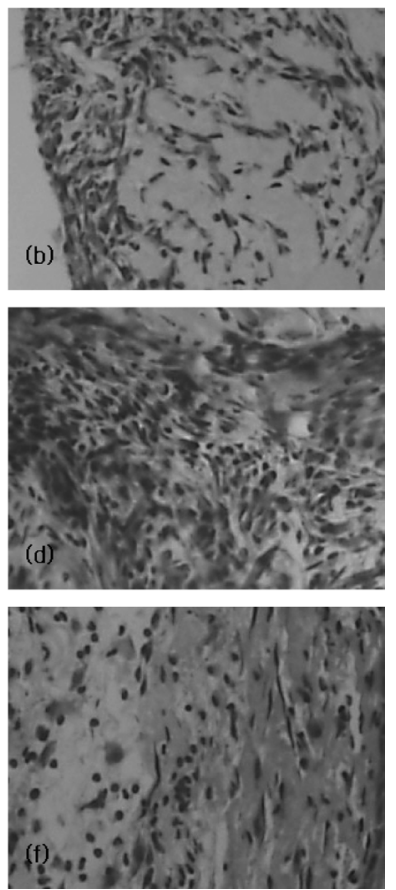

Fig. 10. Histopathological Studies at $5 \mathrm{~d}$ after Injury

Left photographs (a, c, e) and right photograpsh (b, d, f) were that treated with PVA hydrogel without clindamycin and that treated with PVA hydrogel with clindamycin, respectively. A and B; control, a and b; only PVA, c and d; $10 \%$ SA, e and f; $30 \%$ SA.

Our results suggested that clindamycin could play an important role on preventing bacterial infection of the wound. ${ }^{7)}$

PVA is the biodegradable and nontoxic polymer. The natural polymer, SA, is cheap and very useful for wound dressing. As PVA and SA had high aqueous solubility, they needed crosslinking to be applied to the human body as a wound dressing system. Most of the crosslinking method use chemical agent having toxic ketone group. PVA hydrogels produced by freezing-thawing method form a physically crosslinked polymeric chains containing uncrosslinked polymer and water. These gels are non-toxic, non-carcinogenic, and have good biocompatibility and desirable physical properties. In this work, crosslinked hydrogels were prepared at the various proportion of SA to PVA, 0, 5, 10, 20 and $30 \%$. Increasing the concentration of SA, decreased the gelation $\%$, maximum strength and break elongation; and increased the swelling ability and elasticity of hydrogel film. Furthermore, the amounts of proteins adsorbed on hydrogel were increased with increasing sodium alginate ratio, indicating the reduced blood compatibility. In vivo experiments showed that the addition of SA is expected to improve utility as wound dressing mildly. Clindamycin could play an important role on preventing bacterial infection of the wound.

\section{CONCLUSION}

In conclusion, the clindamycin-loaded wound dressing developed using freezing-thawing method with PVP and SA gave more swellable, flexible and elastic compared to that with only PVA. Furthermore, it showed positive healing effect similar to that with only PVA. Thus, it could be used as a potential wound dressing form with better forming and well healing effect of clindamycin.

Acknowledgement This research was supported by the Regional R\&D Cluster Project designated by the Ministry of Science and Technology \& the Ministry of Commerce, Industry, and Energy (2008) and financially supported by the Ministry of Science and Technology (M1041403000105N1403-00140) in South Korea.

\section{REFERENCES}

1) Dyson M., Young S. R., Pendle L., Webster D. F., Lang S., J. Invest. Dermatol., 91, 434-439(1991).

2) Eaglstein W. H., Pittsburgh M. D., J. Am. Acad. Dermatol., 12, 434 440 (1985).

3) Suzuki Y., Tanihara M., Nishmura Y., Suzuki K., Kakimura Y., Shimizu Y., Asaio. J., 43, 854-857 (1997).

4) Tanihara M., Suzuki Y., Nishimura Y., Suzuki K., Kakimaru Y., Peptides, 19, 421—425 (1998).

5) Winter G. D., Nature (London), 193, 293-294 (1962).

6) Platzer D. J., White B. A., J. Pharm. Biomed. Anal., 41, 84-88 (2006).

7) Batzias G. C., Delis G. A., Koutsoviti-Paradopoulou M., J. Pharm. Biomed. Anal., 35, 545-554 (2004).

8) Yeo J. H., Lee K. G., Kim H. C., Oh Y. L., Kim A. J., Kim S. Y., Biol. Pharm. Bull., 23, 1220-1223 (2000).

9) Peppas N. A., Stauffer S. R., J. Controlled Release, 16, 305-310 (1991).

10) Ng R. W., Cheng Y. L., J. Burn. Care. Res., 28, $203-204$ (2007).

11) Patel H. A., U.S. Patent 5,470,576 (1993).

12) Gilchrist T., Martin A. M., Biomaterials, 4, 317-320 (1983).

13) Ajji Z., Othman I., Rosiak J. M., Beam Interact. Mater. Atoms, 229, 375-380 (2005).

14) Balakrishnan B., Mohanty M., Umashankar P. R., Jayakrishnan A., Biomaterials, 26, 6335-6342 (2005).

15) Choi Y. S., Hong S. R., Lee Y. M., Song K. W., Park M. H., Nam Y. S., Biomaterials, 20, 409-417 (1999).

16) A. A. Alencar de Q. H., Humberto G. F., Gustavo A. A., Maria M. F., Antonio L. B., Julio S. R., J. Biomed. Mater. Res., 64A, 147-154 (2003). 
16) Lin W. C., Yu D. G., Yang M. C., Biointerfaces, 47, $43-49$ (2006).

17) Wu M., Bao B., Yoshii F., Makuuchi K., J. Radioanal. Nucl. Ch., 250, $391-395(2001)$

18) Peppas N. A., Scott J. E., J. Controlled Release, 18, 95-100 (1992).

19) You Y., Park W. H., Ko B. M., Min B. M., J. Mater. Sci. Mater. Med., 15, 297-301 (2004)

20) Suzuki Y., Tanihara M., Nishimura Y., Suzuki K., Yamawaki Y., Kudo H., Kakimaru Y., Shimizu Y., J. Biomed. Mater. Res., 48, 522-527 (1999).

21) Burkatovskaya M., Tegos G. P., Swietlik E., Demidova T. N., Castano A., Hamblin M. R., Biomaterials, 27, 4157-4164 (2006).

22) Kim H. J., Choi E. Y., Oh J. S., Lee H. C., Park S. S., Cho C. S., Bio- materials, 21, 131-141 (2000).

23) Park S. N., Kim J. K., Suh H., Biomaterials, 25, 3689-3698 (2004).

24) Yokoyama F., Masada I., Shimamura K., Ikawa T., Monobe K., Colloid. Polym. Sci., 264, 595-601 (1986).

25) Rosiak M. T., Darmawan D., Zainuddin S., Radiat. Phys. Chem., 62 $107-113(2001)$.

26) Ravi P. S. D., Ramakrishna H. V., Raais K., Varada R. A., J. Appl. Polym. Sci., 90, 33-39 (2003).

27) Dion I., Baquey C., Havlik P., Monties J. R., Int. J. Artif. Organs., 6 , $545-550$ (1993).

28) Knighton D. R., Silver I. A., Hunt T. K., Surgery, 90, 262-270 (1981). 